\title{
Piloting proactive marketing to recruit disadvantaged adults to a community-wide obesity prevention program
}

\author{
Blythe J O'Haraa, ${ }^{a}$, Dianne Eggins ${ }^{b}$, Philayrath Phongsavan ${ }^{a}$, Andrew J \\ Milata,c, Adrian E Baumana and John Wiggers ${ }^{\text {d,e }}$
}

a Sydney School of Public Health, University of Sydney, NSW, Australia

b Cancer Institute NSW, Sydney, Australia

- Centre for Epidemiology and Evidence, NSW Ministry of Health, Sydney, Australia

${ }^{d}$ Centre for Population Health, NSW Ministry of Health, Sydney, Australia

e School of Medicine and Public Health, University of Newcastle, NSW, Australia

${ }^{\dagger}$ Corresponding author: blythe.ohara@sydney.edu.au

\section{Article history}

Publication date: March 2015

Citation: O'Hara BJ, Eggins D,

Phongsavan P, Milat AJ, Bauman AE,

Wiggers J. Piloting proactive marketing to recruit disadvantaged adults to a community-wide obesity prevention program. Public Health Res Pract. 2015;25(2):e2521521. doi: http://dx.doi. org/10.17061/phrp2521521

\section{Key points}

- Proactive marketing strategies show promise as an effective way to recruit socioeconomically disadvantaged populations to a telephone-based preventive health coaching program

- Proactive marketing strategies may provide a supplementary recruitment method to facilitate optimal population reach among vulnerable populations

- Populations who were recruited to a six-month telephone-based preventive health coaching program via a proactive marketing strategy reported lifestyle behavioural and anthropometric improvements consistent with participants who self-referred or who were referred by a health practitioner

\section{Abstract}

Population-wide obesity prevention and treatment programs are fundamental to addressing the increasing overweight and obesity rates in socioeconomically disadvantaged populations. Innovative recruitment strategies, including proactive marketing strategies, are needed to ensure such programs have universal reach and target vulnerable populations. This study aimed to determine the success of proactive recruitment to Australia's Get Healthy Information and Coaching Service ${ }^{\circledR}$ (GHS) and to assess whether the recruitment strategy influenced participants' outcomes. Sociodemographic information was collected from all GHS participants who joined the service between February 2009 and August 2013, and anthropometric information regarding behavioural risk factors was collected from all GHS coaching participants at baseline and six months. Data were analysed according to the participants' referral source (self-referral and secondary referral versus proactive recruitment). Participants recruited through proactive marketing were more likely to be male, aged 50 years or older, have high school education, not be in paid employment and be from the lowest three quintiles of socioeconomic advantage. The risk factor profile of coaching participants recruited through proactive marketing did not vary significantly from those recruited via other mechanisms, although they were less likely to be obese and less likely to have a higher 'at risk' waist circumference measurement. Proactively recruited coaching participants reported significant improvements from baseline to six months (consistent with improvements made by participants recruited through other strategies), although they were significantly more likely to withdraw from coaching before they completed the six-month program. Proactive marketing facilitated use of an obesity prevention service; similar services may have greater reach if proactive marketing recruitment strategies are used. These strategies could be encouraged to assist such services to achieve optimal population impact among hard-to-reach populations. 


\section{Introduction}

In Australia, as in many developed countries, people living in socioeconomically disadvantaged areas are more likely to be overweight or obese, have inadequate diet, engage in lower levels of physical activity and have significantly higher rates of chronic disease. ${ }^{1}$ The burden of chronic disease risk factors on socioeconomically disadvantaged populations relative to wealthier groups is evident worldwide. Limited access to affordable preventive health programs and other barriers may widen existing inequalities in health. Further, some preventive health programs may not benefit members of the population equally and, if they benefit more socioeconomically advantaged groups, may generate further inequalities. ${ }^{2}$ Given the prevalence of overweight and obesity across the globe and its associated costs ${ }^{3,4}$, accessible population-wide obesity prevention and treatment programs are needed to support lifestyle modification for adults of lower socioeconomic status.

Based on evidence regarding the efficacy of telephone coaching services ${ }^{5}$, the Get Healthy Information and Coaching Service $\AA$ (GHS) was established in New South Wales (NSW), Australia, as a free service to support adults at risk of chronic disease (www.gethealthynsw.com.au). The community-wide program is available to NSW adults to assist participants to be more physically active, eat healthier food and achieve or maintain a healthy weight. As well as providing tailored and personalised support to achieve behaviour change, telephone coaching can be easily accessible by populations living in rural and remote areas. As such, it has the potential to reduce the disease burden of those of lower socioeconomic status and of hard-to-reach populations who typically have worse health risk profiles.

Since 2009, the GHS has offered participants information on physical activity, nutrition and healthy weight, and/or a six-month telephone coaching program to assist them to reach healthy lifestyle goals. ${ }^{6}$ Participants have been mostly recruited through self-referral (e.g. mass media advertising, including television, press, radio and digital) and secondary referral pathways (e.g. health professionals, workplaces, friends, family), which have been effective at recruiting substantial numbers of participants at risk of chronic disease because of their sociodemographic and risk factor profiles. ${ }^{7}$ However, in August 2011, it was determined that a more targeted, proactive recruitment strategy should be trialled to supplement these universal recruitment strategies, in an effort to bolster service use by more socioeconomically disadvantaged adults. Other population-wide services such as smoking quitlines have previously shown proactive recruitment to be effective. ${ }^{8-10}$ The transferability of this approach to telephone-based services addressing other health risks has recently been 'hypothetically' tested ${ }^{11}$ and found to be acceptable, but its effectiveness in real-world settings has not been reported.
This study examined the relative success of a proactive recruitment method compared with standard recruitment practices, in terms of 1) the sociodemographic characteristics of GHS participants, 2) their risk factor profiles and 3) their anthropometric and behavioural risk factor changes.

\section{Methods}

\section{Design, setting and participants}

A descriptive study of all GHS participants took place between February 2009 and August 2013, including those who self-referred to the GHS, were referred by their health practitioner or joined the GHS as a result of a proactive recruitment strategy.

\section{Proactive recruitment}

The proactive recruitment strategy used a database (www.impactlists.com.au) containing publicly listed names, addresses and phone numbers of all low socioeconomic households in NSW (third and fourth quintile of disadvantage, as determined by the SocioEconomic Indexes for Areas [SEIFA], an index measuring area-level socioeconomic status). ${ }^{12} \mathrm{~A}$ random sample was selected from the database and mailed a GHS 'letter of introduction' and brochure. GHS staff contacted the person via telephone to invite them to join the GHS; up to three telephone call attempts (different day and time of the week) were made.

\section{Data collection procedures and measures}

\section{Sociodemographic characteristics of participants}

A computer-assisted telephone interview was used to collect sociodemographic characteristics (sex, date of birth, postcode, highest education level, employment status, language spoken at home and Indigenous status) of all GHS participants. Participants' postcodes were used to determine their area-level socioeconomic status ${ }^{12}$ and rurality. ${ }^{13}$ Participants were asked their referral source (how they heard about GHS): self-referral (mass media advertising), secondary referral sources (general practitioner, health professional, workplace/employer, and friends and family) or proactive marketing.

\section{Risk factor characteristics of coaching participants}

Self-reported weight $(\mathrm{kg})$, height $(\mathrm{cm})$ and waist circumference $(\mathrm{cm})$ were collected from GHS coaching participants at baseline and six months. Body mass index $\left(\mathrm{BMI}, \mathrm{kg} / \mathrm{m}^{2}\right.$ ) was calculated and classified into categories ${ }^{14}$, and waist circumferences risk categories were also calculated. ${ }^{15}$ Physical activity was assessed using three validated questions, and categories for sufficient physical activity were calculated. ${ }^{16}$ Reported daily consumption of fruit and vegetables was collected and classified according to recommended levels of consumption. ${ }^{17}$ 


\section{Coaching participant status}

Information was also collected by the service provider on the status of coaching participants at any point in time that is, whether they were still active within the coaching program, whether they had graduated or whether they had withdrawn from the program.

Informed consent was obtained from all participants. The study was approved by the University of Sydney Human Research Ethics Committee (ref no. 022009/11570 and 20110906/14113).

\section{Statistical analysis}

GHS usage data were analysed to examine recruitment pathways into the program. Participants were classified as either 'information-only' (received an information package) or 'coaching' (participated in 10 individually tailored coaching calls).

Chi-square tests were used to examine the relationships between 1) referral source, participant sociodemographic variables and coaching status, and 2) referral source and coaching participants' anthropometric and behavioural risk factor profile. Differences in anthropometric and behavioural risk factor measurements were examined using matched paired t-tests and nonparametric tests (Wilcoxon), where appropriate, stratified by referral source. A one-way, between-group analysis of covariance (ANCOVA) was used to assess the impact of referral source on anthropometric and behavioural risk factor changes following coaching program completion, adjusting for baseline values. SPSS 21.0 (IBM SPSS Inc. 2013) was used for all analyses.

\section{Results}

\section{Participants' sociodemographic characteristics}

Between February 2009 and August 2013, 23384 people registered with the GHS and $92.9 \%(n=22$ 183) consented to participate in the study. One-quarter of participants $(25.6 \%)$ were provided with the one-off information kit, and the remaining $74.4 \%$ registered in the coaching program. Of these coaching registrants, $21.6 \%$ withdrew before commencement, and $78.4 \%$ of participants commenced coaching. Of these, $59.1 \%$ withdrew from coaching before the end of the six months, $12.1 \%$ were still active within the coaching program and $28.6 \%(n=3701)$ had completed coaching at the time of the study census.

Overall, the majority ( $80.1 \%$ ) of GHS participants were 'self-referred' (i.e. mass media, family/friends, workplaces), $11.7 \%$ were referred by health professionals (including general practitioners) and $8.1 \%$ were recruited through proactive marketing. The characteristics of participants by referral source are shown in Table 1 . Participants who were recruited through proactive marketing were more likely to be male, aged 50 years or older, have high school education, not be in paid employment and be from the lowest three quintiles of socioeconomic advantage.

Figure 1. Participant flowchart

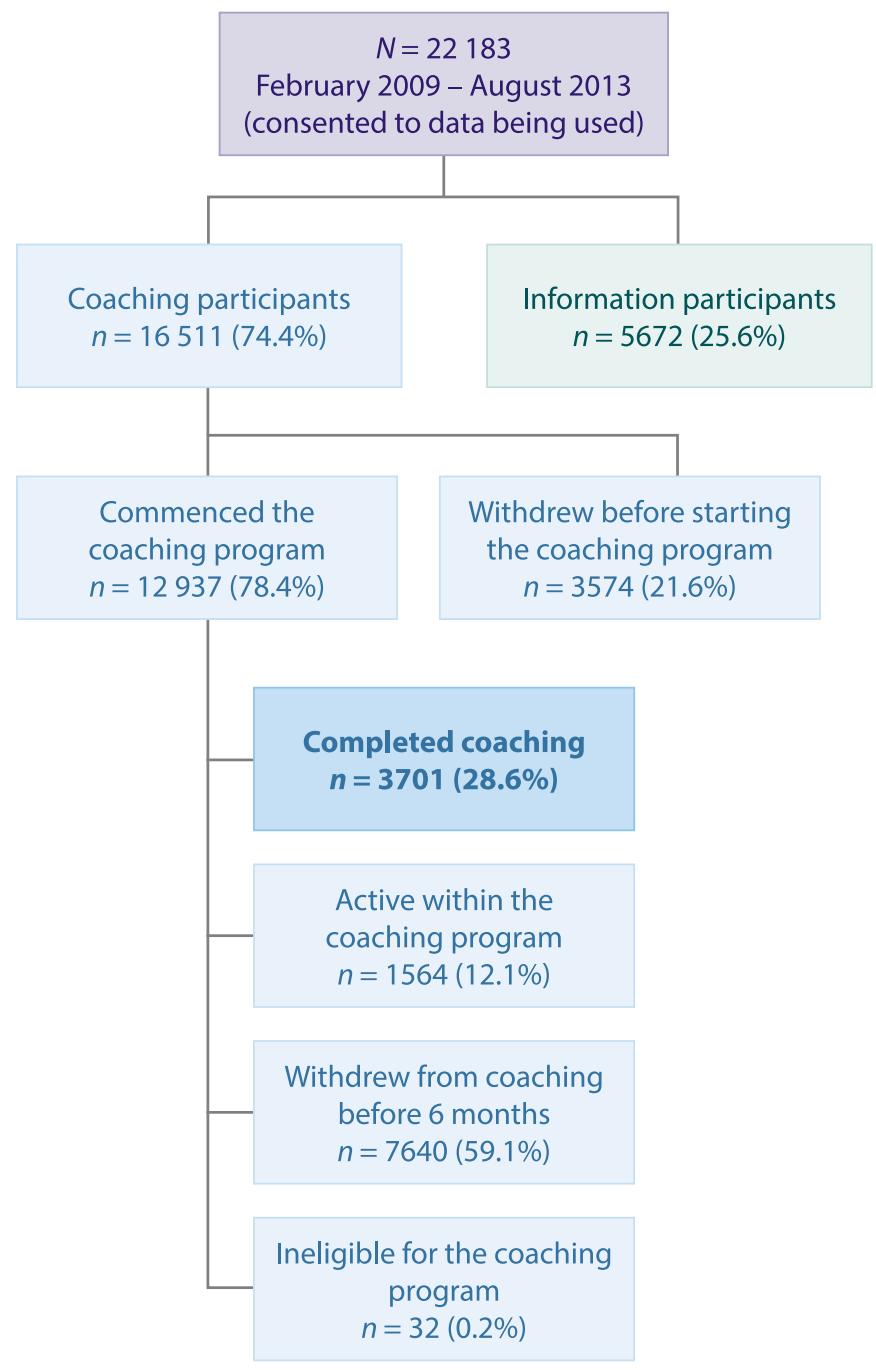

\section{Risk factor characteristics of coaching participants}

The behavioural risk factor profile of coaching participants recruited through proactive marketing did not vary significantly from those recruited via other mechanisms. However, there was a trend that people recruited through proactive marketing were less likely to be obese and less likely to have an increased 'at risk' waist circumference measurement (Table 2). Mean weight, BMl and waist circumference differed significantly between participants referred by all other avenues and those who were proactively recruited. Those recruited through proactive marketing, on average, weighed less (mean $84.8 \mathrm{~kg}$, standard deviation [SD] 19.6, versus mean $87.5 \mathrm{~kg}, \mathrm{SD}$ 21.0; $p=0.009$ ), had a smaller waist circumference (mean $99.9 \mathrm{~cm}, \mathrm{SD} 14.6$, versus mean $102.1 \mathrm{~cm}, \mathrm{SD} 15.9$; $p=0.02$ ) and had a lower BMI (mean 30.1 units, SD 6.5, 
Table 1. Sociodemographic characteristics of all GHS participants by referral source

\begin{tabular}{|c|c|c|c|c|c|c|c|c|}
\hline \multirow[b]{3}{*}{ Characteristic } & \multirow[b]{3}{*}{ Subcharacteristic } & \multicolumn{6}{|c|}{ Referral source } & \multirow[b]{3}{*}{$p$ value } \\
\hline & & \multicolumn{2}{|c|}{ Mass media and other } & \multicolumn{2}{|c|}{$\begin{array}{l}\text { Health professional } \\
\text { and general } \\
\text { practice }\end{array}$} & \multicolumn{2}{|c|}{ Proactive marketing } & \\
\hline & & $n$ & $\%$ & $n$ & $\%$ & $n$ & $\%$ & \\
\hline Total $^{b}$ & & 17753 & 80.8 & 2430 & 11.1 & 1800 & 8.2 & \\
\hline \multirow[t]{2}{*}{ Sex } & Female & 13095 & 73.8 & 1858 & 76.5 & 1002 & 55.7 & $<0.0001$ \\
\hline & Male & 4658 & 26.2 & 572 & 23.5 & 798 & 44.3 & \\
\hline \multirow[t]{2}{*}{ Age } & $18-49$ years & 8864 & 49.9 & 1146 & 47.2 & 449 & 24.9 & $<0.0001$ \\
\hline & $\geq 50$ years & 8889 & 50.1 & 1284 & 52.8 & 1351 & 75.1 & \\
\hline \multirow[t]{2}{*}{ Education } & High school education & 7527 & 42.5 & 1304 & 53.8 & 974 & 54.2 & $<0.0001$ \\
\hline & Other ${ }^{\mathrm{C}}$ & 10173 & 57.5 & 1122 & 46.2 & 823 & 45.8 & \\
\hline \multirow[t]{2}{*}{ Employment } & Full-time/part-time/casual & 9973 & 56.3 & 1088 & 44.8 & 735 & 40.8 & $<0.0001$ \\
\hline & Other $^{d}$ & 7748 & 43.7 & 1339 & 55.2 & 1065 & 59.2 & \\
\hline \multirow[t]{2}{*}{ Aboriginal } & Non-Aboriginal & 17288 & 97.4 & 2177 & 89.7 & 1767 & 98.3 & $<0.0001$ \\
\hline & Aboriginal & 453 & 2.6 & 250 & 10.3 & 31 & 1.7 & \\
\hline \multirow{2}{*}{$\begin{array}{l}\text { Language } \\
\text { spoken at home }\end{array}$} & English & 16335 & 92.0 & 2294 & 94.4 & 1703 & 94.6 & $<0.0001$ \\
\hline & Other & 1418 & 8.0 & 136 & 5.6 & 97 & 5.4 & \\
\hline \multirow[t]{2}{*}{ Region } & Major cities & 11038 & 62.2 & 1103 & 45.4 & 1076 & 59.8 & $<0.0001$ \\
\hline & Other & 6707 & 37.8 & 1326 & 54.6 & 724 & 40.2 & \\
\hline \multirow[t]{2}{*}{ SEIFA } & $\begin{array}{l}\text { 1st and 2nd quintiles (most } \\
\text { advantaged) }\end{array}$ & 5579 & 31.4 & 555 & 22.8 & 28 & 1.6 & $<0.0001$ \\
\hline & $3 \mathrm{rd}, 4$ th and 5 th quintiles & 12174 & 68.6 & 1875 & 77.2 & 1772 & 98.4 & \\
\hline \multirow[t]{2}{*}{ Participant type } & Information & 4579 & 25.8 & 498 & 20.5 & 461 & 25.6 & $<0.01$ \\
\hline & Coaching & 13174 & 74.2 & 1932 & 79.5 & 1339 & 74.4 & \\
\hline
\end{tabular}

SEIFA = Socio-Economic Index for Area

a Linear by linear association test of significance undertaken to test for differences between source of referral

b $N=21983$ (missing data for 200 participants in relation to their referral source; and further missing data for nine participants for region)

c Other education includes diplomas, certificates and tertiary education

d Other employment includes retired, unemployed, home duties and other

versus mean 31.5 units, SD $7.1 ; p=0.001)$, although there were no significant differences in their baseline BMI categories (Table 2). There were no differences between average levels of physical activity or fruit and vegetable consumption.

\section{Anthropometric and behavioural changes between baseline and six months}

All participants, regardless of referral source, reported significant improvements from baseline to six months in:

- weight (mean weight loss $3.9 \mathrm{~kg}$, SD 5.1, $p<0.0001$ ),

- waist circumference (mean decrease $5.0 \mathrm{~cm}, \mathrm{SD} 6.0$, $p<0.0001)$

- $\mathrm{BMI}$ (mean decrease 1.4 BMI units, SD 1.8, $p<0.0001)$

- number of 30-minute walking sessions per week (mean additional 1.2 sessions, SD 2.9, $p<0.0001$ )
- number of 20-minute vigorous physical activity sessions per week (mean additional 0.4 sessions, SD 1.5, $p<0.0001)$

- number of 30-minute moderate physical activity sessions per week (mean additional 0.7 sessions, SD 1.5, $p<0.0001$ )

- daily serves of vegetables (mean additional 1.3 serves, SD 1.5, $p<0.0001$ )

- daily serves of fruit (mean additional 0.4 serves, SD 1.2, $p<0.0001$ )

- daily consumption of sweetened drinks (mean decrease of 0.3 serves, SD $0.9, p<0.0001$ )

- weekly consumption of take-away meals (mean decrease of 0.5 serves, SD 1.2, $p<0.0001$ ). 
Table 2. Baseline sociodemographic, anthropometric and behavioural risk factor characteristics of coaching participants by referral source

\begin{tabular}{|c|c|c|c|c|c|c|c|c|}
\hline \multirow[b]{3}{*}{ Characteristic } & \multirow[b]{3}{*}{ Subcharacteristic } & \multicolumn{6}{|c|}{ Referral source } & \multirow[b]{3}{*}{$p$ value } \\
\hline & & \multicolumn{2}{|c|}{ Mass media and other } & \multicolumn{2}{|c|}{$\begin{array}{l}\text { Health professional } \\
\text { and general practice }\end{array}$} & \multicolumn{2}{|c|}{ Proactive marketing } & \\
\hline & & $n$ & $\%$ & $n$ & $\%$ & $n$ & $\%$ & \\
\hline Total $^{\mathrm{b}}$ & & 10356 & & 1623 & & 913 & & \\
\hline \multirow[t]{2}{*}{ Sex } & Female & 7786 & 75.2 & 1248 & 76.9 & 546 & 59.8 & $<0.0001$ \\
\hline & Male & 2570 & 24.8 & 375 & 23.1 & 367 & 40.2 & \\
\hline \multirow[t]{2}{*}{ Age } & $18-49$ years & 5319 & 51.4 & 776 & 47.8 & 292 & 32.0 & $<0.0001$ \\
\hline & 50 years + & 5037 & 48.6 & 847 & 52.2 & 621 & 68.0 & \\
\hline \multirow[t]{2}{*}{ Education } & High school education & 4070 & 39.4 & 872 & 53.8 & 431 & 47.2 & $<0.0001$ \\
\hline & Certificate/degree/higher & 6263 & 60.6 & 749 & 46.2 & 482 & 52.8 & \\
\hline \multirow[t]{2}{*}{ Employment } & $\begin{array}{l}\text { Employed (full/part-time, } \\
\text { casual) }\end{array}$ & 6020 & 58.2 & 751 & 46.3 & 458 & 50.2 & $<0.0001$ \\
\hline & Other & 4323 & 41.8 & 870 & 53.7 & 455 & 49.8 & \\
\hline \multirow[t]{2}{*}{ Aboriginal } & Non-Aboriginal & 10113 & 97.7 & 1419 & 87.6 & 896 & 98.2 & $<0.0001$ \\
\hline & Aboriginal & 233 & 2.3 & 201 & 12.4 & 16 & 1.8 & \\
\hline \multirow{2}{*}{$\begin{array}{l}\text { Language } \\
\text { spoken at home }\end{array}$} & English & 9582 & 92.5 & 1533 & 94.5 & 866 & 94.9 & 0.001 \\
\hline & Other & 774 & 7.5 & 90 & 5.5 & 47 & 5.1 & \\
\hline \multirow[t]{2}{*}{ Region } & Major cities & 6391 & 61.7 & 753 & 46.4 & 547 & 59.9 & $<0.0001$ \\
\hline & Other & 3961 & 38.3 & 870 & 53.6 & 366 & 40.1 & \\
\hline \multirow[t]{2}{*}{ SEIFA } & $\begin{array}{l}\text { 1st and 2nd quintiles } \\
\text { (most advantaged) }\end{array}$ & 3336 & 32.2 & 384 & 23.7 & 19 & 2.1 & $<0.0001$ \\
\hline & $3 r d, 4$ th and 5 th quintiles & 7020 & 67.8 & 1239 & 76.3 & 894 & 97.9 & \\
\hline \multirow[t]{3}{*}{$\begin{array}{l}\text { BMI } \\
\text { classifications }\end{array}$} & $\begin{array}{l}\text { Under and healthy weight } \\
\text { (BMI 10-24.9) }\end{array}$ & 1504 & 15.4 & 121 & 8.3 & 170 & 19.2 & NS \\
\hline & Overweight (BMI 25-29.9) & 3276 & 33.6 & 325 & 22.3 & 336 & 37.9 & \\
\hline & Obese (BMI $\geq 30)$ & 4966 & 51.0 & 1013 & 69.4 & 380 & 42.9 & \\
\hline Waist & No risk & 787 & 10.7 & 84 & 7.2 & 123 & 16.8 & NS \\
\hline \multirow{2}{*}{$\begin{array}{l}\text { circumference } \\
\text { risk }^{\circ}\end{array}$} & Increased risk & 1270 & 17.3 & 107 & 9.1 & 155 & 21.1 & \\
\hline & Greatly increased risk & 5277 & 72.0 & 979 & 83.7 & 455 & 62.1 & \\
\hline $\begin{array}{l}\text { Fruit and } \\
\text { vegetable }\end{array}$ & $\begin{array}{l}\text { Less than } 2 \text { serves of fruit } \\
\text { daily }\end{array}$ & 5036 & 52.6 & 705 & 51.5 & 455 & 51.2 & NS \\
\hline \multirow[t]{3}{*}{ consumption } & $\begin{array}{l}2 \text { or more serves of fruit } \\
\text { daily }\end{array}$ & 4537 & 47.4 & 665 & 48.5 & 434 & 48.8 & \\
\hline & $\begin{array}{l}\text { Less than } 5 \text { serves of } \\
\text { vegetables daily }\end{array}$ & 8483 & 88.6 & 1187 & 86.6 & 783 & 88.1 & NS \\
\hline & $\begin{array}{l}5 \text { or more serves of } \\
\text { vegetables daily }\end{array}$ & 1091 & 11.4 & 183 & 13.4 & 106 & 11.9 & \\
\hline \multirow[t]{2}{*}{ Physical activity ${ }^{d}$} & Insufficient & 6489 & 67.8 & 953 & 69.6 & 605 & 68.1 & NS \\
\hline & Sufficient & 3088 & 32.2 & 417 & 30.4 & 284 & 31.9 & \\
\hline
\end{tabular}

$\mathrm{BMI}=$ body mass index; NS = not significant; SEIFA = Socioeconomic Index for Areas

a Linear by linear association test of significance undertaken based on referral source

b $N=12937$ coaching participants who commenced coaching (missing data for approximately 45-70 participants, dependent on the referral source and the variable of interest; waist circumference had missing data from 3700 participants; BMI had missing data from 846 participants)

c Waist circumference risk: no risk is $\leq 80 \mathrm{~cm}$ for women and $\leq 94 \mathrm{~cm}$ for men; increased risk is between 81 and $88 \mathrm{~cm}$ for women, and between 95 and $102 \mathrm{~cm}$ for men; greatly increased risk $>88 \mathrm{~cm}$ for women and $>102 \mathrm{~cm}$ for men ${ }^{15}$

d Sufficient physical activity: $\geq 5$ sessions/week walking, or $\geq 5$ sessions/week moderate activity, or 3-4 sessions/week walking and $\geq 1-2$ sessions/week moderate activity, or $\geq 1-2$ sessions/week walking and 3-4 sessions/week moderate activity ${ }^{16}$ 


\section{Withdrawal from the coaching program}

Participants recruited through the proactive marketing strategy were also significantly more likely to withdraw before completing the coaching program $(72.9 \%$ compared with $67.6 \%$ for all other referral sources, $p<0.001)$. Further, proactively recruited participants were more likely to withdraw before their first coaching call than participants recruited through other methods (43.6\% versus $30.7 \% ; p<0.001$ ) (data not shown).

\section{Discussion}

To influence population-based obesity levels, communitywide programs such as the GHS require diverse and complementary recruitment strategies supplemented by targeted methods to recruit those most in need. This study has demonstrated the usefulness of proactive marketing for encouraging individuals - including those in higher-risk groups - to participate in a telephone-based lifestyle intervention program, using an approach that has been demonstrated to be effective for other telephonic risk factor interventions. ${ }^{8-10}$ Importantly, this study also confirms previous research that the GHS reaches socioeconomically disadvantaged communities ${ }^{18}$, and that implementing a strategic recruitment strategy contributes to lessening the potential for intervention-generated inequalities. $^{2}$

Proactive marketing for the GHS was particularly successful at recruiting males who were high school educated, aged over 50 years and not in paid employment. The effectiveness in recruiting males is particularly important, since men are less likely to access health services ${ }^{19}$, seek help or be interested in losing weight. ${ }^{20}$

The greater participation by older adults and those not in paid employment is also encouraging, given their likely greater prevalence of chronic disease risks. ${ }^{21}$ Similarly, participation by those with the least education suggests that the proactive marketing approach can reach an important subpopulation for chronic disease prevention, given their greater prevalence of health risks, lower levels of health literacy ${ }^{22}$ and lower likelihood of accessing health services. ${ }^{23}$

This study confirms, as previously reported ${ }^{18}$, that those using the coaching service have a risk factor profile requiring GHS support. Although there were differences between proactive recruits and self-referred and secondary-referred participants in relation to waist circumference and weight, the differences are only of degrees of risk - approximately $75-80 \%$ of the proactively recruited participants were still at risk based on their weight or waist circumference measurement. Further, the levels of noncompliance with healthy lifestyle recommendations affirm that those who have been proactively recruited to the GHS will benefit from its services. ${ }^{24}$ It would be interesting to explore whether there are ways to use proactive marketing strategies that are targeted based on the risk factor profile of potential participants, rather than their sociodemographic profile, so that a greater proportion of participants who are overweight or obese can be recruited.

This study has shown that proactively recruited participants who complete the coaching program make the same degree of lifestyle changes as those who selfreferred or were referred by a health practitioner. This confirms the value of proactively 'selling' a service to a potential at-risk population in increasing motivation to make lifestyle changes.

This study also shows that those participants who were recruited via proactive marketing were less likely to start the coaching program and were more likely to withdraw from the coaching program before the six-month completion; however, nearly one-third of proactively recruited participants graduated or were still active within the coaching program. Although this is not ideal, it is worth noting that, as an individualised intervention ${ }^{24}$, participants are able to withdraw as determined by their own needs, and the overall 'loss to follow-up' is consistent with drop-out levels reported elsewhere. The decision to invest in proactive marketing as a recruitment strategy, given its effectiveness to recruit vulnerable populations, needs to be carefully considered within the context of the greater likelihood that such participants may not complete the six-month coaching program. ${ }^{25,26}$

Some study characteristics should be considered when interpreting these findings. The study involves participants using practice-based rather than researchsourced data - as such, the findings have strong external validity and utility. The study data involved self-report, so the possibility exists that limitations of participant recall and social desirability bias may have influenced the data provided. Ideally, this study would be supplemented by data on the cost of implementing the proactive marketing strategy, and data on the number of adults who were contacted (via the proactive marketing strategy) and declined to join the GHS; however, such data are not available.

\section{Conclusion}

Based on these results, proactive marketing shows promise as an effective recruitment strategy for a community-wide obesity prevention and treatment program. For such services to achieve optimal population effects among hard-to-reach populations, proactive approaches could be encouraged. However, further work is needed to investigate the cost and effectiveness of proactive marketing according to different vulnerable groups, and also to investigate the effectiveness of possible retention strategies. 


\section{Acknowledgements}

The authors wish to acknowledge the Centre for Population Health and the Office of Preventive Health, NSW Ministry of Health, for funding the GHS and its independent evaluation by the University of Sydney. The authors would also like to acknowledge the staff at Medibank Health Solutions, the contracted suppliers of GHS, for their implementation of the proactive marketing approach, and the GHS participants.

\section{Competing interests}

None declared

\section{References}

1. Australian Institute of Health and Welfare. Australia's health 2012. Canberra: Australian Institute of Health and Welfare; 2012 [cited 2015 Mar 12]. Available from: www. aihw.gov.au/publication-detail/?id=10737422172

2. Lorenc T, Petticrew M, Welch P, Tugwell V. What types of interventions generate inequalities? Evidence from systematic reviews. J Epidemiol Community Health. 2013;67(2):190-3.

3. Australian Bureau of Statistics. National health survey: summary of results, 2007-2008. Canberra: Australian Bureau of Statistics; 2009 [cited 2015 Mar 12]. Available from: http://www.abs.gov.au/ausstats/abs@.nsf/mf/4364.0

4. Colagiuri S, Lee CM, Colagiuri R, Magliano D, Shaw JE, Zimmet PZ, et al. The cost of overweight and obesity in Australia. Med J Australia. 2010;192(5):260-4.

5. Goode AD, Reeves MM, Eakin EG. Telephone-delivered interventions for physical activity and dietary behavior change: an updated systematic review. Am J Prev Medicine. 2012:42(1):81-8.

6. O'Hara BJ, Bauman AE, Eakin EG, King L, Haas M, Allman-Farinelli $\mathrm{M}$, et al. Evaluation framework for translational research: case study of Australia's Get Healthy Information and Coaching Service. Health Promot Pract. 2013;14(3):380-9

7. O'Hara BJ, Bauman AE, Phongsavan P. Using massmedia communications to increase population usage of Australia's Get Healthy Information and Coaching Service $\Re$. BMC Public Health. 2012;12:762.

8. Tzelepis F, Paul CL, Walsh RA, Wiggers J, Knight J, Lecathelinais $C$, et al. Telephone recruitment into a randomized controlled trial of Quitline support. Am J Prev Med. 2009;37(4)324-9.

9. Tzelepis F, Paul CL, Walsh RA, Wiggers J, Duncan SL, Knight J, et al. Active telephone recruitment to quitline services: are nonvolunteer smokers receptive to cessation support? Nicotine Tob Research. 2009:11(10)1205-15.
10. Paul CL, Wiggers J, Daly JB, Green S, Walsh RA, Knight $\mathrm{J}$, et al. Direct telemarketing of smoking cessation interventions: will smokers take the call? Addiction. 2004:99(7):907-13.

11. Wolfenden L, Wiggers J, Paul C, Freund M, Lecathelinais C, Wye P, et al. Increasing the use of preventative health services to promote healthy eating, physical activity and weight management: the acceptability and potential effectiveness of proactive telemarketing approach. BMC Public Health. 2012;12:953.

12. Australian Bureau of Statistics. Information paper: an introduction to socioeconomic indexes for areas (SEIFA). Canberra: Australian Bureau of Statistics; 2006 [cited 2015 Mar 12]. Available from: www.abs.gov.au/ausstats/ abs@.nsf/mf/2039.0/

13. Australian Institute of Health and Welfare. Rural, regional and remote health: a guide to remoteness classifications. Canberra: Australian Institute of Health and Welfare; 2006 [cited 2015 Mar 12]. Available from: www.aihw.gov.au/ publication-detail/?id=6442467589

14. World Health Organization. Obesity: preventing and managing the global epidemic. Report of a WHO consultation (WHO technical report series 894). Geneva World Health Organization; 2000 [cited 2015 Mar 12]. Available from: www.who.int/nutrition/publications/obesity/ WHO_TRS_894/en/

15. Diabetes Australia Guideline Development Consortium. National evidence based guidelines for the management of type 2 diabetes mellitus. Canberra: National Health and Medical Research Council 2001 [cited 2015 Mar 12]. Available from: www.diabetesaustralia.com.au/For-HealthProfessionals/Diabetes-National-Guidelines/

16. Smith BJ, Marshall AL, Huang N. Screening for physical activity in family practice: evaluation of two brief assessment tools. Am J Prev Med. 2005;29(4):256-64. Erratum in: Am J Prev Med. 2006;30(4):363.

17. National Health and Medical Research Council. Australian dietary guidelines. Canberra: National Health and Medical Research Council; 2013 [cited 2015 Mar 12]. Available from: www.nhmrc.gov.au/guidelinespublications/n55

18. O'Hara BJ, Phongsavan P, Venugopal K, Bauman AE. Characteristics of participants in Australia's get healthy telephone-based lifestyle information and coaching service: reaching disadvantaged communities and those most at need. Health Educ Res. 2011;26(5):1097-106.

19. Neville LM, O'Hara BJ, Milat AJ. Computer-tailored dietary behaviour change interventions: a systematic review Health Educ Res. 2009;24(4):699-720.

20. Wardle J, Haase AM, Steptoe A, Nillapun M, Jonwutiwes K, Bellisle F. Gender differences in food choices: the contribution of health beliefs and dieting. Ann Behav Med. 2004;27(2):107-16. 
21. Australian Institute of Health and Welfare, Chronic diseases and associated risk factors in Australia, 2006. Canberra: Australian Institute of Health and Welfare; 2006 [cited 2015 Mar 12]. Available from: www.aihw.gov.au/ publication-detail/?id=6442467914

22. Australian Bureau of Statistics. Australian social trends: health literacy. Canberra: Australian Bureau of Statistics; 2009 [cited 2015 Mar 12]. Available from: www.abs.gov. au/AUSSTATS/abs@.nsf/Lookup/4102.0Main+Features20J une+2009

23. Berkman ND, Sheridan SL, Donahue KE, Halpern DJ, Crotty K. Low health literacy and health outcomes: an updated systematic review. Ann Intern Med. 2011;155:97-107.
24. O'Hara BJ, Phongsavan P, Venugopal K, Eakin EG, Eggins D, Caterson H, et al. Effectiveness of Australia's Get Healthy Information and Coaching Service: translational research with population wide impact. Prev Med. 2012;55(4):292-8.

25. Graffagnino CL, Falko JM, La Londe M, Schaumburg J, Hyek MF, Shaffer LE, et al. Effect of a communitybased weight management program on weight loss and cardiovascular disease risk factors. Obesity (Silver Spring). 2006;14(2):280-8.

26. Moroshko IL, Brennan L, O'Brien P. Predictors of dropout in weight loss interventions: a systematic review of the literature. Obes Rev. 2011;12(11):912-34.

\section{Copyright: (c)(\$)(2)}

(C) 2015 O'Hara et al. This article is licensed under the Creative Commons Attribution-NonCommercial-ShareAlike 4.0 International Licence, which allows others to redistribute, adapt and share this work non-commercially provided they attribute the work and any adapted version of it is distributed under the same Creative Commons licence terms. See: www.creativecommons.org/licenses/by-nc-sa/4.0/ 